\title{
Epiretinal membranes in sickle cell disease
}

\author{
B J MORIARTY, R W ACHESON, AND G R SERJEANT
}

From the Medical Research Council Laboratories (Jamaica), University of the West Indies, Kingston, Jamaica

SUMMARY Epiretinal membranes at the macula were seen in $4 \%$ of the eyes of 355 patients with homozygous sickle cell (SS) disease and sickle cell haemoglobin-C (SC) disease under the age of 60 years. The presence of proliferative sickle retinopathy (PSR), the extent of involvement of PSR, and vitreous haemorrhage all constitute risk factors for the formation of epiretinal membranes. The occlusion of PSR lesions by treatment appears to reduce the risk of epiretinal membranes being formed.

The vaso-occlusive process of sickle cell disease causes a wide variety of ocular disease. Attention has focused on proliferative sickle retinopathy (PSR), its natural history, ${ }^{1-3}$ visual morbidity, and response of these lesions to therapy. ${ }^{4}$ During ophthalmic assessment of Jamaican patients with sickle cell disease it became apparent that macular epiretinal membranes (ERM) developed. The characteristics of such membranes are presented in this report.

\section{Materials and methods}

The patients attended the sickle cell clinic at the University Hospital of the West Indies or a group of peripheral sickle cell clinics operated by the staff of the Medical Research Council (MRC) Laboratories. From 1 October 1983 to 1 October 1985355 patients aged 15-60 years were examined for macular ERM. There were 132 patients with homozygous sickle cell (SS) disease and 223 with sickle cell-haemoglobin C (SC) disease (Table 1). Of this group $41(12 \%)$ patients had been observed twice yearly for three years in an argon scatter study, $30(8 \%)$ twice yearly in a xenon feeder vessel study, ${ }^{4}$ and $284(80 \%)$ annually for at least seven years. The average duration of observation was 6.4 years.

Patients with ERM were recalled for further investigation between 1 October 1985 and 1 January 1986. Assessment included ascertainment of visual symptoms and tests of corrected visual acuity, anterior segment, and intraocular pressure. Direct and indirect ophthalmoscopy were performed after

Correspondence to B J Moriarty, FRCS, Medical Research Council Laboratories (Jamaica), University of the West Indies, Kingston 7 , Jamaica, West Indies. mydriasis. Red-free and colour photographs were taken, and fluorescein angiography was performed where appropriate. The grading of ERMs proposed by Joondeph ${ }^{5}$ was adopted and is illustrated in Figs. 1-4. Additional data recorded included the extent of PSR lesions (clock hours of retina involved), the type of therapy, the visual acuity and grade of ERM when first diagnosed and when last seen, the age and genotype of patients, and the duration of observation.

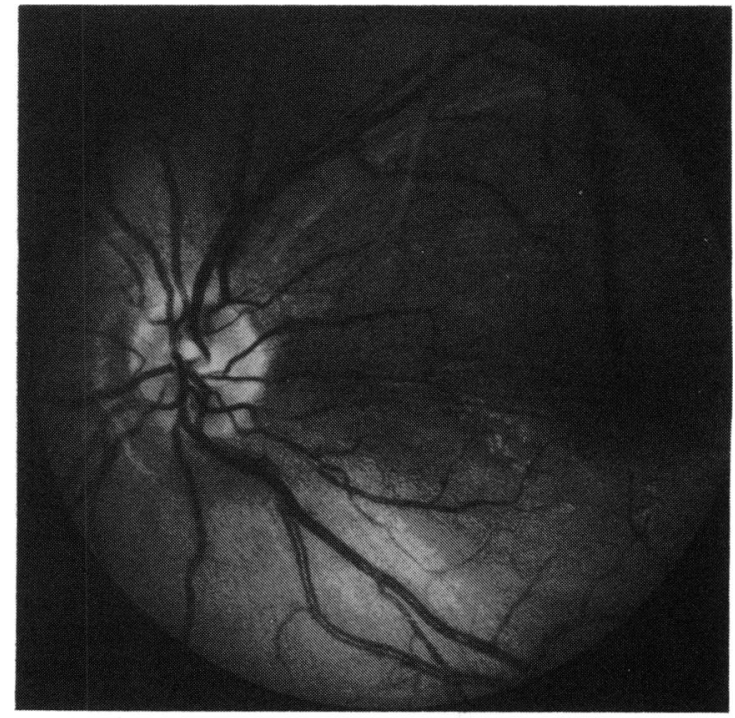

Fig. 1 Red-free photograph of grade I ERM in the left eye of a 23-year-old male with SC disease. Note the altered light reflex, roughened appearance, but absence of retinal distortion. 


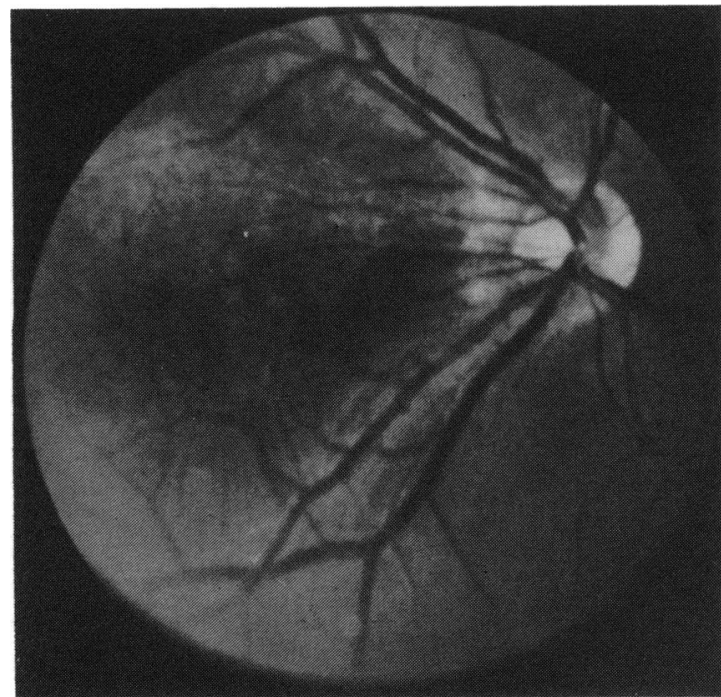

Fig. 2 Red-free photograph of grade II ERM in right eye of a 25-year-old female with SC disease. There is a translucent membrane and some straightening of the papillomacular vessels.

Certain groups were specifically excluded. Patients aged 60 years or over were excluded because of the difficulty in distinguishing age-related ERM in the normal population from those cases associated with sickle cell retinopathy. Eyes with proliferative vitreoretinopathy (PVR) ${ }^{6}$ were excluded unless a preced-

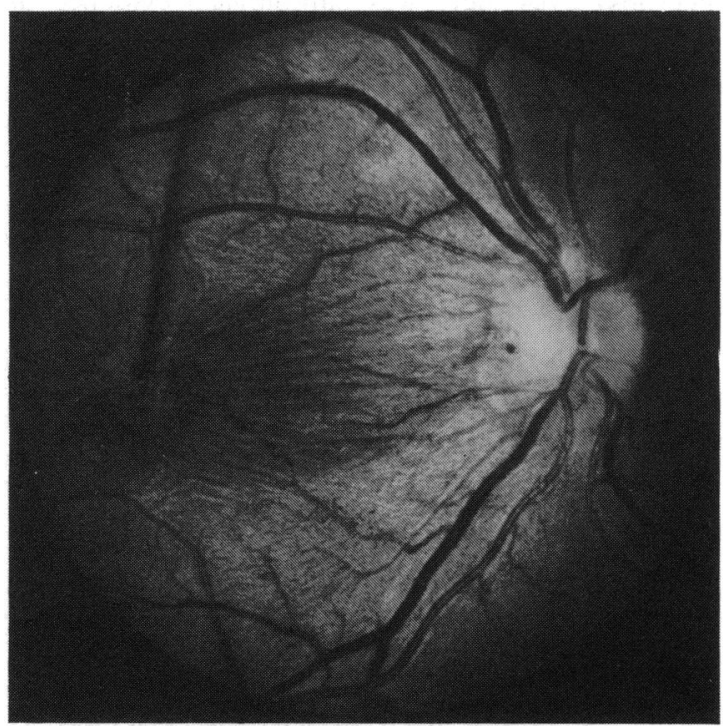

Fig. 3 Red-free photograph of grade III ERM in right eye of a 29-year-old male with SS disease. There are striations of the retina and distortion and tortuosity of retinal vasculature.

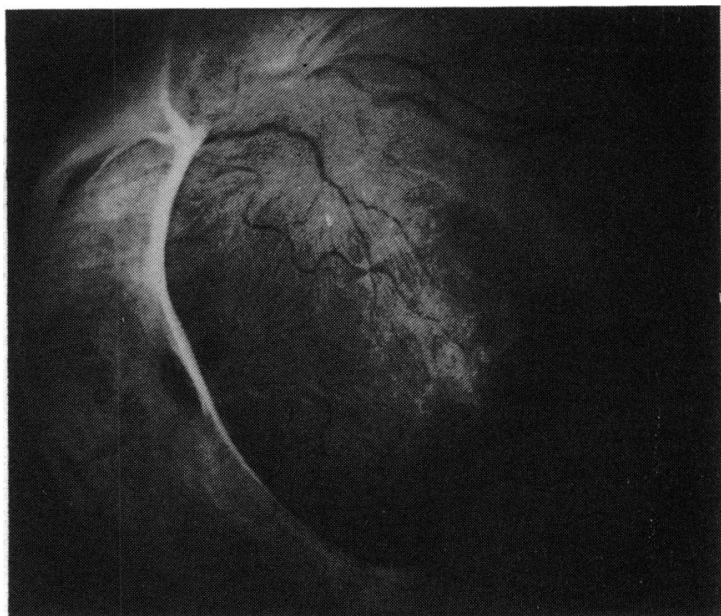

Fig. 4 Red-free photograph of grade IV ERM in the left eye of a 20-year-old female with SC disease. There is a tractional detachment at the superotemporal arcade with a macular hole.

ing localised ERM had been documented. Eyes with macular wrinkling associated with vitreoretinal traction from elevated PSR lesions secondarily involving the posterior pole were excluded. Cataracts prevented assessments of the posterior pole in 11 eyes.

Progression of ERM was deemed to have occurred with advance in grading of the ERM or if a fall in visual acuity of 2 lines or more was sustained on two occasions three months apart and this was not attributable to other pathology.

\section{Results}

Epiretinal membranes were observed in 25 eyes of 24 patients (Table 1) and were bilateral in a 42-year-old male with SS disease. The average age at diagnosis was 37 years (range $24-60$ years).

All ERMs were associated with PSR in the same eye, the prevalence reaching $25 / 236(11 \%)$ of eyes with PSR. They were significantly more common in the SC genotype, but this difference was accounted for entirely by the greater prevalence of PSR in SC disease.

Certain risk factors for ERM formation could be identified. Preliminary observations suggested that ERM formation was related to the extent of PSR, and this was tested by examining data from the 131 eyes admitted to the argon scatter and xenon feeder vessel trials. Within this group there was a highly significant association between ERM and extensive retinal involvement ( $>6$ hours) by PSR $\left(\chi^{2}\right.$ for trend $=21.7 ; \mathrm{p}<0 \cdot 001$ ).

Vitreous haemorrhage also appeared to be a risk 
Table 1 Prevalence of epiretinal membranes according to sex and genotype in patients and in eyes examined

\begin{tabular}{|c|c|c|c|c|c|c|c|c|c|c|c|c|}
\hline & \multicolumn{4}{|l|}{ Male } & \multicolumn{4}{|l|}{ Female } & \multicolumn{4}{|l|}{ Total } \\
\hline & Patients & Eyes & $E R M s$ & (\% eyes) & Patients & Eyes & $E R M s$ & (\% eyes) & Patients & Eyes & $E R M s$ & (\% eyes) \\
\hline SS & 54 & 107 & 3 & (3) & 78 & 154 & 0 & $(0)$ & 132 & 261 & 3 & (1) \\
\hline SC & 110 & 215 & 14 & (7) & 113 & 223 & 8 & (4) & 223 & 438 & 22 & (5) \\
\hline Total & 164 & 322 & 17 & (5) & 191 & 377 & 8 & (2) & 355 & 699 & 25 & (4) \\
\hline
\end{tabular}

factor for ERM formation, ERMs developing in 9/30 $(30 \%)$ eyes with PSR and vitreous haemorrhage compared to 16/206 (8\%) eyes with PSR but without vitreous haemorrhage $\left(\chi^{2}=11.37 ; p<0 \cdot 001\right)$. This relationship might be explicable by the association of vitreous haemorrhage with extensive PSR, which was highly significant in the subgroup of 131 eyes $\left(\chi^{2}\right.$ for trend $=27 \cdot 1 ; p<0 \cdot 001)$ but even after this relationship was allowed for there remained a significant independent effect of vitreous haemorrhage (Mantel-Haenzel $\chi^{2}=4 \cdot 16 ; p=0.04$ ).

The risk of developing an ERM appeared to be reduced by successful therapy of PSR lesions. Thus five patients with bilateral PSR developed ERMs in the untreated eye but never in the successfully treated eye. When analysed in the entire group, ERMs developed in $6 \%$ of treated eyes compared with $17 \%$ of untreated eyes $\left(\chi^{2}=6.62 ; p<0.01\right)$ (Table 2). A similar difference persisted when the analysis was restricted to the eyes of SC patients $\left(\chi^{2}=6 \cdot 61 ; p<0 \cdot 01\right)$. These data suggest that treatment inhibited the development of ERMs, but it is also possible that, if pre-existing ERMs had been considered a contraindication to therapy, such eyes would remain untreated and hence increase the apparent prevalence among untreated eyes. This hypothesis was tested by examining data from the 131 eyes enrolled in the photocoagulation trials, in which 75 were randomised to treatment and 56 to control groups. Subsequent observation indicated the development of ERMs in four unsuccessfully treated eyes ( $5 \%$ of treatment group) and in 10 untreated

Table 2 Prevalence of epiretinal membranes in eyes according to genotype, sex, and treatment of proliferative sickle retinopathy

\begin{tabular}{llll}
\hline & PSR untreated & PSR treated & Total \\
\hline SS M & $2 / 16(12 \%)$ & $1 / 13(8 \%)$ & $3 / 29(10 \%)$ \\
F & $0 / 9(0 \%)$ & $0 / 13(0 \%)$ & $0 / 22(0 \%)$ \\
SS Overall & $2 / 25(8 \%)$ & $1 / 26(4 \%)$ & $3 / 51(6 \%)$ \\
SC M & $10 / 44(23 \%)$ & $4 / 53(8 \%)$ & $14 / 97(14 \%)$ \\
F & $6 / 39(15 \%)$ & $2 / 49(4 \%)$ & $8 / 88(9 \%)$ \\
SC Overall & $16 / 83(19 \%)$ & $6 / 102(6 \%)$ & $22 / 185(12 \%)$ \\
Total & $18 / 108(17 \%)$ & $7 / 128(6 \%)$ & $25 / 236(11 \%)$ \\
\hline
\end{tabular}

eyes (18\% of controls), a significant difference $\left(\chi^{2}=4.04 ; p=0.04\right)$.

Visual acuity was reduced to $6 / 18$ or less in $10 / 25$ $(40 \%)$ of ERM affected eyes and always attributable to the membrane. Acuity of $6 / 60$ or less occurred in two $(8 \%)$ eyes following traction detachment at sites of ERM formation.

Progression was observed in $8 / 25(32 \%)$ of eyes with ERM during a mean observation period of $2 \frac{1}{2}$ years (range six months to seven years). A traction retinal detachment involved the macula in one patient with a fall in visual acuity to $6 / 24$, but vitrectomy and membrane peeling allowed a retinal reattachment, and acuity was maintained at $6 / 12$ nine months postoperatively.

\section{Discussion}

Epiretinal membranes were first described by Ivanoff in 1865.' Synonyms include Cellophane maculopathy, macular pucker, preretinal fibrosis, and surface wrinkling retinopathy. In a study of 1000 necropsy eyes there was pathological evidence of ERM in $5.4 \%$, the prevalence increasing from $2 \%$ at age 50 to $20 \%$ at age $75 .{ }^{8}$ The majority of ERMs are idiopathic and age-related, this group constituting $56 \%$ of the 328 eyes with ERM requiring surgery in a recent review. ${ }^{9}$ Other causes in this study included postretinal detachment $(29 \%)$, retinal vascular disease $(4 \%)$, photocoagulation (3\%), ocular inflammation $(3 \%)$, trauma $(2 \%)$, and vitreous haemorrhage $(1 \%)$. The ophthalmoscopic features are elegantly described by Wise, ${ }^{10}$ and treatment by vitrectomy and membrane peeling has yielded favourable results in many cases. ${ }^{911-13}$

The pathogenesis of ERM formation remains controversial. Simple idiopathic ERMs are thought to result from disruption of the internal limiting membrane by posterior vitreous detachment (PVD). This provides access for glial cells which migrate through breaks in that membrane and proliferate on the retinal surface ${ }^{14}$ is providing a scaffold for fibroblastic elements. ${ }^{16}$ The fibroblastic contractile membrane adherent to the internal limiting membrane causes secondary contraction of the superficial retina. The histopathological review by Clarkson et 
al. ${ }^{17}$ confirmed that glial cells were the predominant cellular type and demonstrated continuity of the ERM with a site of disruption in the internal limiting membrane or with the optic nerve head.

Secondary ERMs are composed of glial cells, fibrocytes, macrophages, and retinal pigment epithelial cells in varying combinations. The fibrocytes and macrophages may be derived from retinal glial cells or from cortical vitreous cells (hyalocytes). Retinal pigment epithelial cells are the major type contributing to ERMs seen in rhegmatogenous retinal detachment..$^{14} 1718$

The present study indicates that sickle cell disease may also be a cause of ERMs. Risk factors for this complication include: $(a)$ the presence of PSR; (b) extensive retinal involvement of PSR ( $>6$ clock hours); (c) non-treatment or unsuccessful treatment of PSR; $(d)$ pre-existing vitreous haemorrhage.

The common association of PSR with PVD may result in discontinuities of the internal limiting membrane and ingress of glial cells. Vitreous haemorrhage from PSRs may contribute by stimulating fibroplasia and activating cortical hyalocytes. Transudation of plasma from PSRs may disorganise the vitreous cortex further to increase the risk of posterior vitreous detachment. Dellaporta ${ }^{19}$ suggested that subclinical, subretinal transudation into the macula from peripheral retinal lesions may contribute to ERMs.

There is insufficient evidence to explain why treatment of PSR reduces the risk of ERM formation. The occlusion of proliferative lesions decreases the risk of vitreous haemorrhage and transudation of plasma. This may decrease the incidence and progression of posterior vitreous detachment, the attendant disruption of the internal limiting membrane, and the subsequent ingress of glial cells.

The present study demonstrates a significant visual morbidity associated with ERM. The development of traction detachment in two eyes $(8 \%$ of those with ERM) was caused by progression of localised ERM at the posterior pole and did not appear to be caused by traction from peripheral sites of vitreoretinal traction - the most frequent cause of traction detachment in proliferative sickle cell retinopathy.

Progression of ERM in sickle cell retinopathy resembles the unpredictable nature of idiopathic ERMs reported by Sidd et al..$^{20}$ They describe a case progressing from $6 / 7.5$ to counting fingers in three months and other cases failing to progress after seven years. Spontaneous separation of ERMs was not observed in the present study but has been reported elsewhere. ${ }^{21} 22$

We thank Professor A C Bird for discussion, Ms G H Maude and Mr D Dunn for statistical assistance, and Mrs S Grant for secretarial help. This study was supported in part by the Wellcome Trust and by
Comprehensive Sickle Cell Grant PHS HL15168 from the National Heart, Lung and Blood Institute, National Institutes of Health, Bethesda, Maryland.

\section{References}

1 Condon PI, Serjeant GR. Ocular findings in hemoglobin SC disease in Jamaica. Am J Ophthalmol 1972; 74: 921-31.

2 Condon PI, Serjeant GR. Ocular findings in homozygous sickle cell anemia in Jamaica. Am J Ophthalmol 1972; 73: 533-43.

3 Condon PI, Serjeant GR. Behaviour of untreated proliferative sickle retinopathy. BrJ Ophthalmol 1980; 64: 404-11.

4 Jampol LM, Condon PI, Farber PM, Rabb M, Ford S. A randomised clinical trial of feeder vessel photocoagulation of proliferative sickle cell retinopathy. Ophthalmology 1983; 90: 540-5.

5 Joondeph HC. The incidence of epiretinal membrane with retinal breaks and detachments. In: Fine SL, Owen SL, eds. Management of retinal vascular and macular disorders. Baltimore: Williams and Wilkins, 1983: 100-1.

6 The Retina Society Terminology Committee. The classification of retinal detachment with proliferative vitreoretinopathy. Ophthalmology 1983; 90: 121-5.

7 Ivanoff A. Beiträge zur Normalen und Pathologischen Anatomie des Auges. Graefes Arch Clin Exp Ophthalmol 1865; 11: $135-70$.

8 Roth AM, Foos FY. Surface wrinkling retinopathy in eyes enucleated at autopsy. Ophthalmology 1971; 75: 1047-58.

9 Margherio R, Cox MS, Trese MT, Murphy PL, Johnson J, Minor LA. Removal of epimacular membranes. Ophthalmology 1985; 92: $1075-80$.

10 Wise GN. Clinical features of idiopathic preretinal macular fibrosis. Am J Ophthalmol 1975; 79: 349-55.

11 Michels RG. Clinical and histopathological study of epiretinal membranes affecting the macula and removed by vitreous surgery. Trans Am Ophthalmol Soc 1982; 30: 580-98.

12 Michels RG, Gilbert HD. Surgical management of macular pucker after retinal reattachment surgery. Am J Ophthalmol 1979; 88: 925-9.

13 Michels RG. Surgery of macular pucker. In: Fine SL, Owens SL, eds. Management of retinal vascular and macular disorders. Baltimore: Williams and Wilkins, 1983: 120-1.

14 Kampik A, Kenyon K, Michels RG, Green WR, de la Cruz Z. Epiretinal and vitreous membranes. Arch Ophthalmol 1981; 99: 1445-54.

15 Bellhorn N, Friedman A, Wise G, Henkind P. Ultrastructure and clinicopathologic correlation of idiopathic preretinal macular fibrosis. Am J Ophthalmol 1975; 79: 366-77.

16 Hiscott PS, Grierson T, Trombetta CJ, Rahi ANS, Marshall J, McLeod D. Retinal and epiretinal glia-an immunohistochemical study. Br J Ophthalmol 1984; 68: 698-707.

17 Clarkson J, Green W, Massof D. A histopathological review of 168 cases of preretinal membrane. Am J Ophthalmol 1977; 84: 1-17.

18 Kampik A, Green W, Michels R, Nase PK. Ultrastructural features of progressive idiopathic epiretinal membranes removed by vitreous surgery. Am J Ophthalmol 1980; 90: 797-809.

19 Dellaporta A. Macular pucker and peripheral retinal lesions. Trans Am Ophthalmol Soc 1973; 71: 329-40.

20 Sidd RJ, Fine SL, Owens SL, Patz A. Idiopathic preretinal gliosis. Am J Ophthalmol 1982; 94: 44-8.

21 Sumers KD, Jampol LM, Goldberg MF, Huamonte FU. Spontaneous separation of epiretinal membranes. Arch Ophthalmol 1980; 98: 318-20.

22 Messner KH. Spontaneous separation of preretinal macular fibrosis. Am J Ophthalmol 1977; 83: 9-11.

Accepted for publication 31 July 1986. 